vegetable sources and probably something like the mucilage extracted from Irish moss. However, paint made in this way might very well suit Indian conditions, and it would be interesting to know more about the actual tests on paints made up with this material and their keeping qualities. Mention is also made of the prospects of growing tung trees in India.

\section{Thames Valley Rainfall}

Some interesting facts and figures relative to the recent rainfall and floods in the Thames Valley were given by Lord Desborough, chairman of the Thames Conservancy Board, at the meeting of the Board on January 13. In the course of his observations, Lord Desborough said that, following the drought which began in July 1933 and continued into August 1935, last year was the wettest year since 1924. The total rainfall, as determined from the twelve stations in the Thames catchment area, was 33.9 inches, that is, $5 \cdot 66$ inches above the standard annual average and greater even than that of the year 1894, which was the year notable for the unprecedented volume of a flood, recorded at Teddington as 20,000 million gallons during a 24-hour day in the month of November. On August 12 last, the flow was only $261,300,000$ gallons, the lowest ever recorded on a single day. During the recent heavy rains, the flow at Teddington had reached 9,000 million gallons on January 3, as compared with 2,407 million gallons which was the standard daily average for the month of January. On January 13, the flow had fallen to 6,000 million gallons, which was still 1,500 million gallons above the figure at which the river ran bank high. Lord Desborough thinks the public can look forward with some confidence to a good supply of water next summer from the springs and tributaries, despite the fact that since the drought of 1933 there is still a deficiency of $4 \cdot 27$ inches in the rainfall, a fact which shows the severity of the drought. He alluded to various schemes which have been mooted for dealing with floods in the Thames and other areas, and stated that a scheme brought out in 1914 for dealing with the Thames floods was estimated to cost $£ 3,000,000$. The authorities concerned said they would prefer the floods. The cost at the present time would be about double that amount. As regards the construction of reservoirs to contain the surplus flow, the Queen Mary Reservoir of the Metropolitan Water Board, the largest they have, cost $£ 2,000,000$ and holds $6,600,000,000$ gallons-only about one day's flow under such conditions as have recently prevailed.

\section{Wireless Equipment on the Queen Mary}

According to an article in World Radio of January 10, the 75,000 ton Cunard-White Star liner, the Queen Mary, will possess wireless equipment in keeping with the high reputation she has already acquired as a modern trans-Atlantic express liner. The transmitting and receiving rooms are on the boat deck and separated by a distance of about 250 feet. The four transmitters are operated remotely from the receiving end, which acts as the control room for the whole of the ship's radio equipment. This room contains eight operating positions, tho radio-telephone exchange and the emergency installation; and it is in direct telephone connexion with the bridge and all other important positions in the ship. The various services to be undertaken by the Queen Mary while at sea will involve the use of thirty-two wave-lengths, eleven of which are for short-wave telegraphy, nine for radio-telephony, seven for long-wave and five for medium-wave telegraphy. By co-operation with the British Post Office and the International Telephone and Telegraph Corporation of New York, two-way radio-telephone conversation to practically any part of the world will be possible at any time; and two independent conversations may take place simultaneously with the aid of the usual devices for ensuring secrecy. This service will be available from any one of the five hundred state-rooms, each of which is fitted with a bedside telephone, while for passengers in all classes, numerous telephone booths in various parts of the ship will be available. In addition to the apparatus for normal radio com. munication, a music- and speech-amplifying installation is provided for the simultaneous relaying of three different programmes in the public rooms through thirty-eight loud-speakers. An extensive library of gramophone records of all types will be carried in the ship to supplement the orchestral music and broadcasting programmes normally provided.

\section{Australian National Research Council}

DEFINITE proposals for a radical modification of the Australian National Research Council have been drafted for submission to its members and to those of the Australian and New Zealand Association for the Advancement of Science. Though constituted under the ægis of the latter body in 1921, the Research Council has hitherto functioned quite independently of it. It is now proposed that the A.N.Z.A.A.S. should institute a limited fellowship, the original fellows to be past and present presidents, general treasurers and general secretaries of itself and of the A.N.R.C., together with presidents and past presidents of sections and not more than fifty others selected for special qualifications, giving a total of between 120 and 150. Subsequent elections would be made annually by the fellows, with adequate safeguards to ensure the maintenance of a high standard. The fellows of the Association resident in Australia would then be appointed a Committee with the title "Australian National Research Council" and with duties similar to those of the body at present carrying that name. The new Council would take over the assets of the existing one, and the A.N.Z.A.A.S. would place at its disposal for research and other purposes a sum not exceeding one half of the sub. scriptions of fellows and annual members.

THIs plan, if adopted, will bring about a very desirable intimate contact between the Research Council and the Association, which in itself is a loose federation of practically all the scientific societies and institutions in Australia and New Zealand. The 